\title{
PREPARATION AND PROPERTIES OF ALKALI-ACTIVATED CEMENT CONTAINING PHOSPHOROUS SLAG AND FLY ASH
}

\author{
DUO YOU, "YONGHAO FANG, CHENHUI ZHU, YONGFAN GONG, YAMIN GU \\ College of Mechanicsand Materials, Hohai University, Nanjing 210098, P.R. China \\ \#E-mail: fangyh@hhu.edu.cn
}

Submitted September 10, 2015; accepted January 7, 2016

\begin{abstract}
Keywords: Alkali-activated cement, Phosphorous slag, Fly ash, Setting time, Strength, Carbonation resistance, Frost resistance, Microstructure

Phosphorous slag is an industrial waste which potentially pollutes environments. The aim of the present work is to use phosphorous slag as a raw material to produce alkali-activated cement. The influence of mix proportion of phosphorous slag and fly ash, alkali content and modulus of water glass on the properties of alkali-activated phosphorous slag and fy ash cement $(A A-P S-F A-C)$ was studied. The results show that $A A-P S-F A-C$ with normal setting performance and desirable mechanical properties can be prepared using water glass as the activator. Changing the fly ash content in the range of 0 - 40 wt. \% has only a small influence on the setting time of AA-PS-FA-C. The strengths significantly decrease when the fy ash content exceeds $30 \mathrm{wt} . \%$. The carbonation resistance of AA-PS-FA-C is similar to that of ordinary Portland cement $(O P C)$, while the frost resistance is much better. The hardened paste of AA-PS-FA-C is much more compact than OPC paste.
\end{abstract}

\section{INTRODUCTION}

Alkaline cement has attracted widespread attention because of its simple production process, full utilization of industrial waste as raw materials, low pollution and good performance [1-3]. The mostly investigated waste for preparing alkaline cement is granulated blast furnace slag (GBFS), which has good potential hydraulic properties [4-11]. Since GBFS has been widely used in the production of ordinary Portland cement and concrete, and there is a shortage of the slag supplement, it is necessary to seek new resources to substitute GBFS.

Phosphorous slag is an industrial waste from yellow phosphorus production. Quenched phosphorous slag is composed mainly of amorphous material and its chemical and mineral composition is similar to GBFS, so that it is expected to be a possible material resource to prepare alkali-activated cement. But before use it is of course necessary to carry out comprehensive studies on alkali-activated phosphorous slag cement. Fly ash is also an industrial waste. Although now being widely used in cement and concrete, its utilization is still unsatisfactory. Nevertheless, there has been quite a few reports concerning alkali-activated fly ash cement, and the effect of fly ash as the raw material for alkaliactivated cement has been gradually recognized [12-14]. With respect to the aforementioned facts, the preparation of alkali-activated cement containing both phosphorous slag and fly ash seems to be possible.
This paper mainly studies the influence of mix proportion of phosphorous slag and fly ash, alkali content and module of water glass on the properties of alkali-activated phosphorous slag and fly ash cement (AA-PS-FA-C). The results of a preliminary study on the carbonation and frost-resistance of AA-PS-FA-C are reported as well.

\section{EXPERIMENTAL}

\section{Materials}

Granulated phosphorous slag (PS) from Yunnan Phosphorus Group Co., Ltd and Class II fly ash (FA) conforming to Chinese standard GB/T 1596-2005 [15] from Nanjing Huaneng Power Plant, water glass (WG), and chemical reagent $\mathrm{NaOH}$ were used as the raw materials. Two ordinary Portland cements, Chinese $\mathrm{P} \cdot \mathrm{II} 42.5$ (PII) and P.O42.5 (PO) both conforming to GB 175-2007 [16], were used as the references, and ISO

Table 1. Chemical compositions of phosphorous slag and fly ash wt. \%.

\begin{tabular}{crrrrrrrr}
\hline Material & $\mathrm{SiO}_{2}$ & $\mathrm{Al}_{2} \mathrm{O}_{3}$ & $\mathrm{Fe}_{2} \mathrm{O}_{3}$ & $\mathrm{CaO}$ & $\mathrm{MgO}$ & $\mathrm{P}_{2} \mathrm{O}_{5}$ & $\mathrm{SO}_{3}$ & $\mathrm{IL}^{*}$ \\
\hline PS & 41.23 & 4.40 & 4.87 & 44.06 & 0.27 & 1.44 & - & 1.70 \\
FA & 49.76 & 32.88 & 4.04 & 3.67 & 1.09 & - & 0.63 & 2.32 \\
\hline
\end{tabular}

* Mass loss after being ignited at $950^{\circ} \mathrm{C}$ for $20 \mathrm{~min}$. 
standard sand was used for preparing mortar specimens. The chemical compositions of PS and FA as analyzed by Jiangsu Test and Analysis Center with chemical methods according to JC/T 1088-2008 [17] and GB/T 176-2008 [18], respectively, are shown in Table 1.

Experimental procedures

\section{Preparation of $A A-P S-F A-C$}

PS and FA were ground to have Blaine specific surface areas of $435 \mathrm{~m}^{2} \cdot \mathrm{kg}^{-1}$ and $463 \mathrm{~m}^{2} \cdot \mathrm{kg}^{-1}$, respectively. Water glass with different concentrations and $\mathrm{SiO}_{2} / \mathrm{Na}_{2} \mathrm{O}$ modules were prepared by adding $\mathrm{NaOH}$ and water. AA-PS-FA-C was prepared by mixing the phosphorous slag, fly ash and water glass in designed proportions. The water requirement for normal consistency and setting times were tested according to GB/1346-2001 [18].

\section{Strength test}

The flexural and compressive strengths were tested according to GB/T17671-1999 [19]. Mortar specimens of $40 \mathrm{~mm} \times 40 \mathrm{~mm} \times 160 \mathrm{~mm}$ were prepared with the sand to AA-PS-FA-C ratio 3.0 and the water (including the water contained in the water glass) to $\mathrm{AA}-$ PS-FA-C ratio 0.5. The specimens were cured in the mould at $20( \pm 1)^{\circ} \mathrm{C}$ and relative humidity $(\mathrm{RH})>90 \%$ for 24 hours, and cured in water of $20( \pm 1)^{\circ} \mathrm{C}$ after demoulding. Flexural and compressive strengths were tested at the age of 3 days and 28 days by a TYE-10C flexural and compressive testing machine for cement mortar manufactured by China Wuxi Jianyi Instrument and Machinery Co., Ltd (China). Three specimens were tested each cement at each age according to the standard.

\section{Carbonation and freezing and thawing resistance}

Six mortar specimens of $40 \mathrm{~mm} \times 40 \mathrm{~mm} \times 160 \mathrm{~mm}$ for each set, three for carbonation and the other three for freezing and thawing resistance tests, were prepared and cured for 28 days under the same condition as those for the strength test mentioned above. The carbonation test was performed in an IMHTX-X concrete carbonization test chamber manufactured by INBER (Tianjin) Science and Technology Development Ltd (China), at $20 \pm 1{ }^{\circ} \mathrm{C}$ with the concentration of carbon dioxide $20 \pm 2 \%$ and $\mathrm{RH}=70 \pm 5 \%$. The carbonized depth was tested by $1 \%$ phenolphthalein ethanol solution. The freezing and thawing test was performed using an H-3185 rapid freezing and thawing tester manufactured by Humboldt MFG. Co. (USA) with the freezing and thawing temperatures $-18^{\circ} \mathrm{C}$ and $8^{\circ} \mathrm{C}$, respectively. The duration of each cycle was about 3 hours. The response frequency was tested by a DT-W18 dynamic elastic modulus detector produced by Bejing Jingjing Science and Technology Development Co., Ltd. (China). The relative dynamic elastic modulus was obtained by dividing the square of the response frequency of the specimen subjected to freezing and thawing by the square of the response frequency of the original specimen.

\section{SEM analysis}

Hardened cement paste specimens of ordinary Portland cement and AA-PS-FA-C with normal consistency were prepared and cured at $20( \pm 1)^{\circ} \mathrm{C}$ and $\mathrm{RH}>90 \%$ for 28 days. The paste specimens were sampled and immersed in absolute alcohol for 48 hours to terminate the hydration, and dried at $60^{\circ} \mathrm{C}$ for 10 hours. The fractured sections of the sample were observed by an S-3400N scanning electron microscope (SEM) produced by Hitachi Co., Ltd (Japan), with the accelerating voltage $15 \mathrm{kV}$.

\section{RESULTS AND DISCUSSION}

\section{Setting time and strength \\ Influence of fly ash content}

Table 2 shows the water requirement for normal consistency, setting time and mortar strength of AA-PS-FA-C with different phosphorous slag/fly ash mass ratios. The $\mathrm{SiO}_{2} / \mathrm{Na}_{2} \mathrm{O}$ module of the water glass was 1.2 and the total amount of water glass and $\mathrm{NaOH}$ equivalent to $\mathrm{Na}_{2} \mathrm{O}$ was $4 \%$ of the sum of phosphorous slag and fly ash. The water requirements of AA-PS-FA-C are a little lower than that of the references PII and PO.

Table 2. Physical and mechanical properties of AA-PS-FA-C.

\begin{tabular}{|c|c|c|c|c|c|c|c|c|c|}
\hline \multirow{3}{*}{ Sample } & \multirow{2}{*}{\multicolumn{2}{|c|}{$\begin{array}{l}\text { Mix proportion } \\
\text { (wt. \%) } \\
\end{array}$}} & \multirow{3}{*}{$\begin{array}{c}\text { Water requirement } \\
\qquad(\%)\end{array}$} & \multirow{2}{*}{\multicolumn{2}{|c|}{$\begin{array}{c}\text { Setting time } \\
(\mathrm{min})\end{array}$}} & \multicolumn{4}{|c|}{ Strength (MPa) } \\
\hline & & & & & & \multicolumn{2}{|c|}{ Flexural } & \multicolumn{2}{|c|}{ Compressive } \\
\hline & PS & $\overline{\mathrm{FA}}$ & & initial & $\overline{\text { final }}$ & $3 \mathrm{~d}$ & $28 \mathrm{~d}$ & $3 \mathrm{~d}$ & $28 \mathrm{~d}$ \\
\hline PF0 & 100 & 0 & 25.2 & 140 & 215 & 6.8 & 7.2 & 31.6 & 52.3 \\
\hline PF1 & 90 & 10 & 24.8 & 130 & 200 & 5.8 & 7.0 & 22.5 & 35.4 \\
\hline PF2 & 80 & 20 & 24.6 & 125 & 205 & 4.3 & 6.7 & 20.8 & 30.6 \\
\hline PF3 & 70 & 30 & 24.4 & 130 & 200 & 3.9 & 5.9 & 17.5 & 25.4 \\
\hline PF4 & 60 & 40 & 24.0 & 145 & 230 & 3.3 & 4.8 & 15.4 & 20.3 \\
\hline PII & - & - & 26.0 & 150 & 215 & 6.5 & 7.8 & 24.3 & 53.1 \\
\hline
\end{tabular}


Unlike most alkali-activated blast furnace slag cements, the AA-PS-FA-C set in a normal time. The reason is that the phosphorous slag contains a certain amount of soluble phosphorus, which retards the setting of the alkali-activated cement [7]. Varying the fly ash content in the range $0-40 \%$ has only a small influence on the setting time, especially on the initial setting time. Fly ash is not as active as phosphorous slag, so that adding fly ash can retard the overall reaction and setting process in cementitious materials. On the other hand, adding fly ash reduces the content of soluble phosphorus in the cement, thus the retarding effect of soluble phosphorus is weakened and the setting process accelerates. The influence of fly ash on setting is a combination of the two contradictory effects.

The strength of the AA-PS-FA-C without fly ash (PF0) increased rapidly, attaining compressive strength values as high as $31.6 \mathrm{MPa}$ and $52.3 \mathrm{MPa}$, after 3 days and 28 days, respectively. When fly ash was added, the strength, especially early age strength, significantly decreased, but the strengths of the cementitious materials can still meet the requirement for P-II42.5 cement when the fly ash content does not exceed $20 \%$. When the fly ash content exceeds $30 \%$, the strength of the cementitious materials decrease significantly. The results indicate that the addition of fly ash should be controlled in the range of 10 to $20 \%$ when preparing AA-PS-FA-C.

\section{Influence of alkali content}

Table 3 shows the water requirement for normal consistency, setting time and mortar strength of specimens with different alkali content. The $\mathrm{SiO}_{2} / \mathrm{Na}_{2} \mathrm{O}$ module of the water glass was 1.2 . Adding fly ash in the range of $0-40 \%$ and increasing the $\mathrm{Na}_{2} \mathrm{O}$ level increased the water requirements of the AA-PS-FA-C slightly. It also shortened the initial setting time and increased the flexural and compressive strengths. When the water glass dosage equivalent to $\mathrm{Na}_{2} \mathrm{O}$ was 4 to $6 \%$, the strengths of all the AA-PS-FA-C specimens meet the requirement for P-II42.5 cement. Especially with 10 wt. $\%$ of fly ash and 6 wt. $\%$ of $\mathrm{Na}_{2} \mathrm{O}$, the strengths can meet the requirement for $\mathrm{P} \cdot \mathrm{O} 52.5 \mathrm{R}$ cement [16]. The strengths are basically the same as those reported by Puertas et al for materials prepared with blast furnace slag and fly ash [14]. When $\mathrm{Na}_{2} \mathrm{O}$ is up to $6 \mathrm{wt}$. \%, the AA-PS-FA-C sets too fast. So the dosage of water glass equivalent to $\mathrm{Na}_{2} \mathrm{O}$ should be controlled in the range of 4 to $5 \%$ when preparing AA-PS-FA-C.

\section{Influence of water glass module}

Table 4 shows the basic performance of AA-PS-FA-C with different module of water glass as the activator, the water glass content being equivalent to $4 \% \mathrm{Na}_{2} \mathrm{O}$. When the total content of $\mathrm{Na}_{2} \mathrm{O}$ is the same, increasing the module of water glass increased the water

Table 3. Properties of AA-PS-FA-C with different alkali content.

\begin{tabular}{|c|c|c|c|c|c|c|c|c|c|c|c|c|}
\hline \multirow{3}{*}{ Sample } & \multirow{2}{*}{\multicolumn{2}{|c|}{$\begin{array}{l}\text { Mix proportion } \\
\text { (wt. \%) }\end{array}$}} & \multirow{3}{*}{$\begin{array}{l}\mathrm{Na}_{2} \mathrm{O}^{*} \\
\text { (wt. \%) }\end{array}$} & \multirow{3}{*}{$\begin{array}{c}\text { Water } \\
\text { requirement } \\
(\%)\end{array}$} & \multirow{2}{*}{\multicolumn{2}{|c|}{$\begin{array}{l}\text { Setting time } \\
\quad(\mathrm{min})\end{array}$}} & \multicolumn{6}{|c|}{ Strength $(\mathrm{MPa})$} \\
\hline & & & & & & & \multicolumn{3}{|c|}{ Flexural } & \multicolumn{3}{|c|}{ Compressive } \\
\hline & PS & $\overline{\text { FA }}$ & & & initial & final & $3 \mathrm{~d}$ & $7 \mathrm{~d}$ & $28 \mathrm{~d}$ & $3 \mathrm{~d}$ & $7 \mathrm{~d}$ & $28 \mathrm{~d}$ \\
\hline PF1-1 & 90 & 10 & 3 & 24.6 & 160 & 270 & 3.2 & 4.1 & 5.8 & 16.2 & 25.3 & 32.9 \\
\hline PF1 & 90 & 10 & 4 & 24.8 & 130 & 190 & 4.4 & 5.8 & 7.0 & 22.5 & 35.4 & 51.2 \\
\hline PF 1-2 & 90 & 10 & 5 & 25.4 & 115 & 170 & 5.2 & 6.1 & 8.2 & 26.3 & 38.6 & 58.0 \\
\hline PF1-3 & 90 & 10 & 6 & 26.0 & 60 & 110 & 5.9 & 6.8 & 8.4 & 29.0 & 40.5 & 62.3 \\
\hline PF2-1 & 80 & 20 & 3 & 24.4 & 175 & 260 & 2.8 & 3.9 & 5.5 & 14.2 & 20.1 & 28.5 \\
\hline PF2 & 80 & 20 & 4 & 24.6 & 125 & 175 & 3.8 & 4.3 & 6.7 & 20.8 & 30.6 & 45.5 \\
\hline PF2-2 & 80 & 20 & 5 & 25.2 & 115 & 175 & 4.5 & 5.7 & 7.2 & 23.5 & 35.6 & 50.3 \\
\hline PF2-3 & 80 & 20 & 6 & 25.8 & 80 & 135 & 4.8 & 6.0 & 7.5 & 25.4 & 38.9 & 52.4 \\
\hline
\end{tabular}

* Total amount of water glass and $\mathrm{NaOH}$ equivalent to $\mathrm{Na}_{2} \mathrm{O}$, as the weight percent of the sum of phosphorous slag and fly ash

Table 4. Properties of AA-PS-FA-C activated by water glass with different modulus.

\begin{tabular}{|c|c|c|c|c|c|c|c|c|c|c|c|c|}
\hline \multirow{3}{*}{ Sample } & \multirow{2}{*}{\multicolumn{2}{|c|}{$\begin{array}{l}\text { Mix proportion } \\
\text { (wt. \%) }\end{array}$}} & \multirow{3}{*}{$\begin{array}{c}\text { Module } \\
\text { of water } \\
\text { glass }\end{array}$} & \multirow{3}{*}{$\begin{array}{c}\text { Water } \\
\text { requirement } \\
(\%)\end{array}$} & \multirow{2}{*}{\multicolumn{2}{|c|}{$\begin{array}{l}\text { Setting time } \\
\quad(\mathrm{min})\end{array}$}} & \multicolumn{6}{|c|}{ Strength $(\mathrm{MPa})$} \\
\hline & & & & & & & \multicolumn{3}{|c|}{ Flexural } & \multicolumn{3}{|c|}{ Compressive } \\
\hline & PS & FA & & & initial & final & $3 \mathrm{~d}$ & $7 d$ & $28 \mathrm{~d}$ & $3 \mathrm{~d}$ & $7 \mathrm{~d}$ & $28 \mathrm{~d}$ \\
\hline PF 1-1 & 90 & 10 & 1.0 & 24.2 & 125 & 200 & 4.1 & 5.6 & 7.0 & 23.2 & 30.8 & 46.5 \\
\hline PF1 & 90 & 10 & 1.2 & 24.8 & 130 & 190 & 4.4 & 5.8 & 7.0 & 22.5 & 35.4 & 51.2 \\
\hline PF1-2 & 90 & 10 & 1.5 & 25.2 & 150 & 170 & 4.2 & 6.0 & 7.2 & 20.0 & 35.8 & 49.8 \\
\hline PF1-3 & 90 & 10 & 1.8 & 25.8 & 140 & 180 & 3.0 & 5.2 & 6.3 & 18.5 & 28.3 & 38.5 \\
\hline PF2-1 & 80 & 20 & 1.0 & 24.2 & 130 & 180 & 3.5 & 5.5 & 6.5 & 19.2 & 28.1 & 40.2 \\
\hline PF2 & 80 & 20 & 1.2 & 24.6 & 145 & 210 & 3.8 & 5.3 & 6.7 & 20.8 & 30.6 & 45.5 \\
\hline PF2-2 & 80 & 20 & 1.5 & 25.0 & 140 & 190 & 3.8 & 4.9 & 7.0 & 19.8 & 31.4 & 48.2 \\
\hline PF2-3 & 80 & 20 & 1.8 & 25.2 & 165 & 230 & 2.9 & 3.8 & 5.4 & 16.3 & 25.4 & 32.1 \\
\hline
\end{tabular}


requirements of AA-PS-FA-C slightly. This has only a slight effect on the setting time, but a great influence on mechanical properties. When the module of water glass is $1.2-1.5$, the mechanical properties of AA-PS-FA-C are better.

\section{Carbonation and frost resistance}

Figure 1a shows the changes of carbonation depths of the PF1 and PF2 specimens with carbonation ages. The results of PII and PO cements were also presented for reference. It can be seen from Figure 1a that the carbonation resistances of the PF1 and PF2 specimens were lower than that of PII and PO cements, but the difference is not very significant. The $\mathrm{Ca}(\mathrm{OH})_{2}$ contents in the AA-PS-FA-C pastes are much lower than those in the PII and PO cement pastes, although the carbonation resistances of the two varieties of cements are basically the same. The reasons for that may be as follows: (1) The alkalinity of the pore solution is higher in the alkali-activated phosphorous slag-fly ash cement pastes than those in the PII and PO cement pastes, so that carbonation has less effect on the reducing of basicity of the $\mathrm{NaOH}$ solution; (2) The hardened cement paste of the alkali-activated phosphorous slag-fly ash cement has a more compact structure than those of PII and PO cements, which blocks the entering of $\mathrm{CO}_{3}{ }^{2-}$ ions and delays the carbonation reaction.

Figure $1 \mathrm{~b}$ shows the change of the relative dynamic elastic modulus $\left(P_{n}\right)$ as the function of the cycles $\mathrm{N}$ of freezing and thawing for PF1 and PF2 specimens, respectively. The result for PII and PO cements were also shown in the figure. The results indicate that the freeze/thaw resistances of the mortar specimens of the alkali-activated phosphorous slag-fly ash cement are significantly higher than that of the PII and PO cements. The relative dynamic elastic modulus of the PII and PO cement specimens are less than $60 \%$ of the initial value

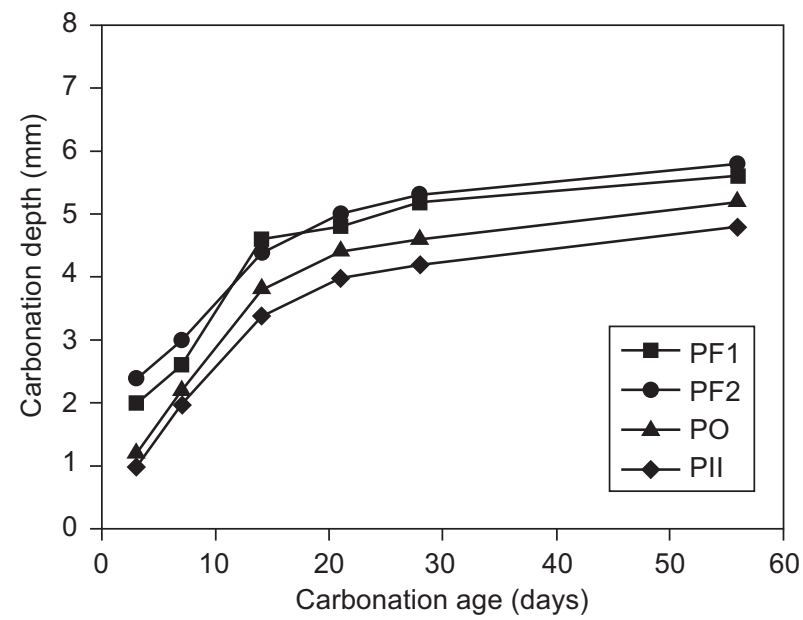

a) after 75 cycles, while those of PF1 and PF2 are still higher than $60 \%$ of the initial value after 125 cycles and 100 cycles, respectively.

\section{Microstructure}

Figures $2 \mathrm{a}$ and $2 \mathrm{~b}$ are the SEM photographs of the hardened PII and PF2 pastes, respectively. PII paste is composed mainly of $\mathrm{C}-\mathrm{S}-\mathrm{H}$ gel, $\mathrm{Ca}(\mathrm{OH})_{2}$ and ettringite, and has a very compact structure. The structure of the PF2 paste is even more compact, and the main components of the paste are $\mathrm{C}-\mathrm{S}-\mathrm{H}$ and $\mathrm{C}-\mathrm{A}-\mathrm{H}$ gels containing some small crystals and glassy particles that probably came from fly ash. $\mathrm{X}$-ray diffraction analysis gives no exact information about the mineral compositions of the crystals.

\section{CONCLUSIONS}

- Alkali-activated phosphorous slag and fly ash ce-ment (AA-PS-FA-C) has normal setting time. Varying the fly ash content in the range $0-40$ wt. \% has only a small influence on the setting time of AA-PS-FA-C.

- Adding fly ash reduces the mechanical properties of AA-PS-FA-C. The strengths significantly decrease when the fly ash content exceeds 30 wt. \%. The optimum content of fly ash is $10-20 \mathrm{wt}$. \%.

- Using water glass with the module of 1.2 as activator, AA-PS-FA-C with desirable strength can be prepared when the dosage of water glass equivalent to $\mathrm{Na}_{2} \mathrm{O}$ is $4-5 \%$ of the sum of the phosphorous slag and fly ash.

- The carbonation resistance of AA-PS-FA-C is similar to that of ordinary Portland cement, while the frost resistance is much better. The hardened paste of AA-PS-FA-C is much more compact than ordinary Portland cement paste.

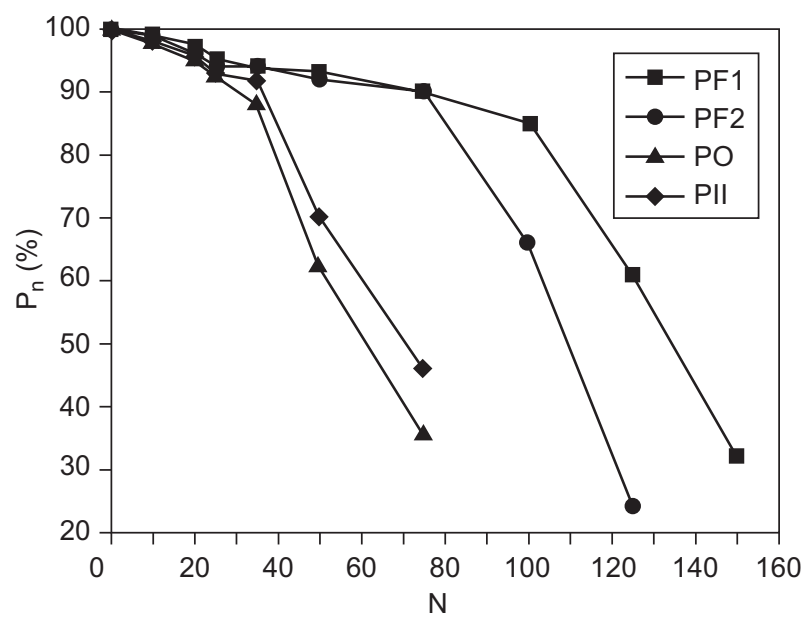

b)

Figure 1. Carbonation and frost resistances of the cements: a) carbonation depth with time; b) relative dynamic elastic modulus with freeze-thaw cycles. 


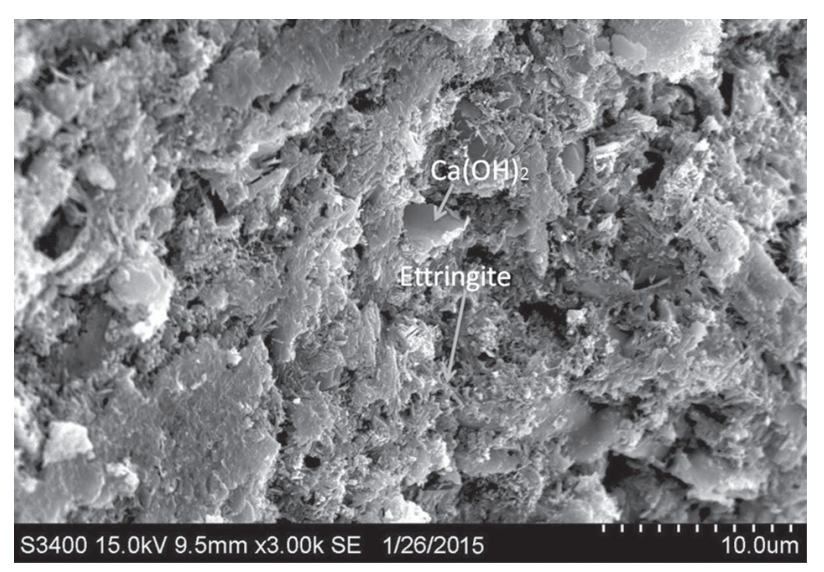

a)

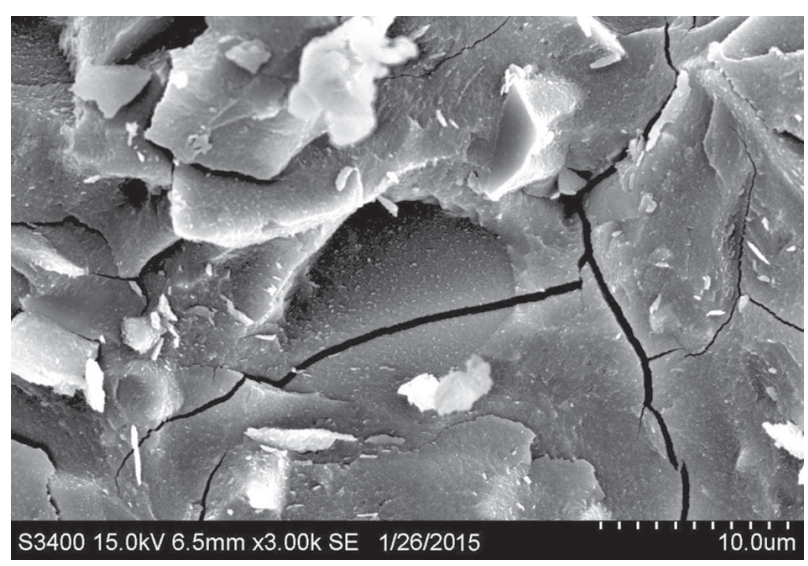

b)

Figure 2. SEM images of AA-PS-FA-C and Portland cement pastes hydrated for 28 days: a) P-II 42.5, b) PF2.

\section{Acknowledgements}

The authors would like to gratefully appreciate the financial support from the National Natural Science Foundation of China (Grant No. 51461135001 and 51139001), and the Provincial Foundation for IndustryUniversity-Research Joint Innovation Cooperation (Grant No. BY2014002-04) of Jiangsu, China.

\section{REFERENCES}

1. Douglas E., Bilodeau A.,Malhotra V.M. (1991): Alkali-activated ground granulated blast-furnace slag concrete: preliminary investigation. Cement and concrete research, 21(1), 101-108. doi:10.1016/0008-8846(91)90036-H

2. Brough A.R., Atkinson A. (2002): Sodium silicate-based, alkali activated slag mortars: Part I. Strength, hydration and microstructure. Cement and Concrete Research, 32(6), 865879. doi:10.1016/S0008-8846(02)00717-2

3. Wu C.N. (1989): Bull. Chin. Ceram. Soc. 1, 25.

4. Gu Y.M., Fang Y.H., You D. (2015): Properties and microstructure of alkali-activated slag cement cured at belowand about-normal temperature. Construction and Building Materials, 79, 1-8. doi:10.1016/j.conbuildmat.2014.12.068

5. Gu Y. M., Fang Y. H. (2012): Shrinkage, Cracking, ShrinkageReducing and Toughening of Alkali-Activated Slag Cement - A Short Review. Journal of the Chinese Ceramic Society, 40(1), 76-84.

6. Fernández-Jiménez A., Palomo J.G., Puertas F. (1999): Alkali-activated slag mortars: mechanical strength behaviour. Cement and Concrete Research, 29(8), 1313-1321. doi:10.1016/S0008-8846(99)00154-4

7. Collins F.G., Sanjayan J.G. (1999): Workability and mechanical properties of alkali activated slag concrete. Cement and Concrete Research, 29(3), 455-458. doi:10.1016/S00088846(98)00236-1

8. Bakharev T., Sanjayan J. G., Cheng Y.-B. (2000): Effect of admixtures on properties of alkali-activated slag concrete. Cement and Concrete Research, 30(9), 1367-1374. doi:10.1016/S0008-8846(00)00349-5

9. Barnett S. J., Soutsos M. N., Millard S. G. (2006): Strength development of mortars containing ground granulated blast-furnace slag: Effect of curing temperature and determination of apparent activation energies. Cement and Concrete Research, 36(3), 434-440. doi:10.1016/j.cemconres. 2005.11.002
10. Bakharev T., Sanjayan J. G., Cheng Y.-B. (1999): Effect of elevated temperature curing on properties of alkali-activated slag concrete. Cement and concrete research, 29(10), 16191625. doi:10.1016/S0008-8846(99)00143-X

11. Aydin S., Baradan B. (2012): Mechanical and microstruc-tural properties of heat cured alkali-activated slag mortars. Materials \& Design, 35, 374-383. doi:10.1016/j.matdes.2011.10.005

12. Xie Z., Xi Y. (2001): Hardening mechanisms of an alkalineactivated class F fly ash. Cement and Concrete Research, 31(9), 1245-1249. doi:10.1016/S0008-8846(01)00571-3

13. Gong C., Yang N. (2000): Effect of phosphate on the hydration of alkali-activated red mud-slag cementitious material. Cement and Concrete Research, 30(7), 1013-1016. doi:10.1016/S0008-8846(00)00260-X

14. Puertas F., Martínez-Ramírez S., Alonso S., Vázquez T. (2000): Alkali-activated fly ash/slag cements: strength behaviour and hydration products. Cement and Concrete Research, 30(10), 1625-1632. doi:10.1016/S0008-8846(00)00298-2

15. China General Administration of Quality Supervision, Inspection and Quarantine (GAQSIQ of China), and China National Standardization Management Committee (NSMC of China): GB/T 1596-2005 Fly ash used for cement and concrete, 2005-01-19.

16. China General Administration of Quality Supervision, Inspection and Quarantine (GAQSIQ of China), and China National Standardization Management Committee (NSMC of China): GB 175-2007 Common Portland cement, 2007-11-09.

17. China National Development and Reform Commission (NDRC of China): JC/T 1088 -2008 Method for chemical analysis of granulated electric furnace phosphorous slag, 2008-06-16.

18. China General Administration of Quality Supervision, Inspection and Quarantine (GAQSIQ of China), and China National Standardization Management Committee (NSMC of China):GB/T 176-2008 Method for chemical analysis of cement, 2008-06-30.

19. China General Administration of Quality Supervision, Inspection and Quarantine (GAQSIQ of China), and China National Standardization Management Committee (NSMC of China): GB/1346-2001 Test methods for water requirement of normal consistency, setting time and soundness of the Portland cement, 2011-07-20.

20. China State Bureau of Quality and Technical Supervision (SBQTS of China): GB/T17671-1999 idt ISO 679:1989 Method of testing cements-Determination of strength, 199902-08. 